patients, but the numbers were small and the length of follow up only between one and five years. ${ }^{518}$ As in many aspects of the management of massive haemoptysis no hard and fast rules have been proved to apply, and decisions will often depend on the preferences of the physicians or surgeons.

D KEVIN JONES Senior Registrar 'ROBERT J DAVIES Consultant

Academic Department of Respiratory Medicine, St Bartholomew's Hospital,

London EC1A 7BE

1 Yeoh CB, Hubaytar RT, Ford JM, Wylie RH. Treatment of massive haemorrhage in pulmonary tuberculosis. F Thorac Cardiovasc Surg 1967;54:503-10.

Corey R, Hla KM. Major and massive haemoptysis: reassessment of conservative management. Am f Med Sci 1987;294:301-9.

3 Crocco JA, Rooney JJ, Fankushen DS, DeBenederto RJ, Lyons HA. Massive haemoptysis. Arch Intern Med 1968;121:495-8.

+ Johnston RN, Lockhart W, Ritchie RT, Smith DH. Haemoptysis. Br.Med J 1960;i:592-5
Bobrowitz ID), Ramakrishna S, Shim Y.S. Comparison of medical v surgical treatment of major haemoptysis. Arch Intern Med 1983:143:13+3-6.

6 Conlan AA, Hurwitz SS, Krige L, Nicolaou N, Pool R. Massive haemoptysis. A review of 123 cases. I Thorac Cardionasc Surg 1983;85:120-4.

Anonymous. Life-threatening haemoptwsis [Editorial]. Lancet 1987; : 1354-6

8 Gourin A, Garzon AA. Operative treatment of massive haemoptysis. Ann Thorac Surg 1974;18:

$52-60$.
9 Sehhat S, Oreizie M, Moinedine K. Massive pulmonary haemorrhage: surgical approach as choice of treatment. Ann Thorac Surg 1978:25:12-5.

10 Stern RC, Wrod RE, Boat TF, Matthews LW, Tucker AS, Dexrshuk CF. Treatment and prognosis of massive haemoptysis in cystic fibrosis. Am Rev Respir Dis 1978;117:825-8.

11 Yang CT, Berger HW. Conservative management of life-threatening hemoptysis. Mt Sinai $7 . M e d$ (NY) 1978; $45: 329-33$

12 Shivaram U, Finch P, Nowak P. Plastic endobronchial tubes in the management of life-threatening hemoptysis. Chest 1987;92:1108-10.

13 Imgrund SP, Goldberg SK, Walkenstein MD, Fischer R, Lippmann ML. Clinical diagnosis of massive haemoptysis using the fibreoptic bronchoscope. Crit Care Med 1985;13:438-43.

4 Saw EC, Gottlieb LS, Yokoyama T, Lee BC. Flexible fibreoptic bronchoscopy and endobronchial tamponade in the management of massive hemoptysis. Chest 1976;70:589-9

Tsukamoto T, Sasaki H, Nakamura H. Treatment of hemoptysis patients by thrombin and famoto T, Sasaki H, Nakamura H. Treatment of hemoptysis patients by thrombin and

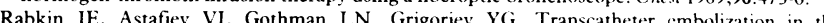
man

management of pulmonary haemorrhage. Radiology 1987;163:361-5. hemoptysis: technical aspects and long-term results. Radiology 1985;157:637-44.

18 Pursel SE, Lindskog GE. Hemoptysis. A clinical evaluation of 105 patients examined consecutivel on a thoracic surgical service. Am Rev Respir Dis 1961;84:329-36.

19 Douglas BE, Carr DT. Prognosis in idiopathic hemoptysis. FAMA 1952;150:764-5.

\title{
Idiopathic dilated cardiomyopathy
}

\section{Rational treatment awaits better understanding of pathogenesis}

Idiopathic dilated cardiomyopathy is a chronic heart muscle disease that predominantly affects young men and causes dilatation and contractile dysfunction of the left or the right ventricle, or both. ${ }^{1}$ In the United States its prevalence is around 20 per 100000 population, and there is an incidence of six new cases per 100000 a year $^{2}$; exact figures for Britain are not available. The diagnosis is made by exclusion; it relies on showing the absence of coronary artery disease, valvular or pericardial disorders, and specific heart diseases.

The usual presentation is with features of heart failure, arrhythmia, or thromboembolism, and the duration of the presymptomatic phase of the illness is uncertain in most patients. For many years it has been thought that dilated cardiomyopathy may be a consequence of previous viral myocarditis. A syndrome very like human dilated cardiomyopathy may be produced in animals after they have had viral myocarditis, but the progression in humans of acute myocarditis to left ventricular dilatation and contractile failure has been described only in isolated case reports. ${ }^{3}$

Although the early natural course of the condition before the development of symptoms remains a matter of speculation, the clinical course after diagnosis is well documented. Published reports agree on the poor prognosis of dilated cardiomyopathy, with two fifths to a half of patients dying within two years after the diagnosis. ${ }^{1+}$ Some patients die in cardiogenic shock or pulmonary oedema, but most deaths seem to be sudden. In the early period after diagnosis sudden death usually occurs in association with progressive impairment of left ventricular function, but it is common at all stages of the disease and may occur in patients who have responded well to treatment with regard to their symptoms and the haemodynamic features of the disease and who have remained stable for some time.

The high incidence of sudden death suggests an arrhythmic cause, and indeed arrhythmias are common regardless of the duration of the disease (one fifth of patients develop chronic atrial fibrillation and two fifths have non-sustained ventricular tachycardia on 24 hour electrocardiographic monitoring). The prognostic implications of ventricular arrhythmias remain controversial, however, and may be different at different stages of the disease. Non-sustained ventricular tachycardia is common in the first two years after diagnosisthe period during which most deaths occur-but these are generally in association with progressive heart failure (though details of the mode of death are frequently lacking in published work). Thereafter there is an annual mortality of about $4 \%$, with most deaths apparently being sudden. The influence of ventricular arrhythmia on survival may be more important in later stages in patients whose heart failure is well controlled but who die suddenly.

Conventional treatment makes very little difference to survival and has no impact on the progression of the disease. Indeed our imperfect understanding of the disease processes that underlie dilated cardiomyopathy means that treatment remains empirical. In practical terms it is restricted to the relief of symptoms of heart failure with diuretics, angiotensin converting enzyme inhibitors, and (perhaps) digoxin and the prevention of thromboembolic complications with coumarin anticoagulants. ${ }^{1}$ The only treatment option that has been shown to improve prognosis is heart transplantation, and patients with dilated cardiomyopathy account for more than half of all recipients of heart transplants. ${ }^{6}$

Treatment with antiarrhythmic agents has not been shown to improve prognosis in patients with dilated cardiomyopathy except in those patients who present with episodes of sustained ventricular tachycardia and those in whom the disease predominantly affects the right ventricle. ${ }^{7}$ Although this group of patients is small, sustained monomorphic ventricular tachycardia of right ventricular origin is a prominent feature of their disease. Aggressive management of the arrhythmia, including drug treatment and surgical approaches, is warranted; if life threatening arrhythmias can be suppressed the prognosis is good, as left ventricular dysfunction is usually minimal.

The report of the cooperative north Scandinavian enalapril survival study (CONSENSUS) study of the effect of the angiotensin converting enzyme inhibitor enalapril in the treatment of older patients (mean age 70 years) with severe 
heart failure (in whom the principal diagnosis was ischaemic heart disease) was the first clear evidence that medical treatment (as opposed to heart transplantation) could improve the prognosis of patients in grade IV heart failure. ${ }^{8}$ The impact of this treatment on prognosis in patients with dilated cardiomyopathy has not yet been established.

The clinical picture outlined above highlights the deficiencies in our understanding of dilated cardiomyopathy. When these are added to the combination of a high mortality and our apparent failure to alter prognosis the conclusion must be that more basic research is required. At present most patients are investigated to show cardiac structure and function, and those aged over 30 will probably undergo coronary arteriography to exclude coronary artery disease. Though this approach establishes the diagnosis, it has provided little useful information about the mechanisms of pathogenesis and their relation to outcome. Endomyocardial biopsy has comprised part of the investigation of patients with dilated cardiomyopathy in some centres, but its usefulness has been much argued. Without doubt specific myocardial disease (such as cardiac sarcoid) may be detected by endomyocardial biopsy, but more commonly the histological appearances are non-specific, showing loss of myocytes and their replacement by fibrous tissue. Attempts to find a relation among clinical state, outcome, and the biopsy findings have been disappointing, but recent work on quantitative microscopy suggests that there may be a good correlation between myofibrillar volume or myocyte area and left ventricular contractile function and prognosis. ${ }^{910}$ Endomyocardial biopsy should be mandatory if acute myocarditis is suspected as the presence of active inflammation and destruction of myocytes warrants empirical treatment by immunosuppression with steroids and either cyclophosphamide or azathioprine.

Although the progression of acute viral myocarditis to dilated cardiomyopathy seems to be rare, persistent viral infection remains an important hypothesis for explaining the development of this condition. Corroborative evidence for this theory came with the discovery of raised titres of antibody to coxsackieviruses in patients with dilated cardiomyopathy. Slot blot and in situ hybridisation techniques have shown enterovirus RNA sequences in cardiac tissue in $20-30 \%$ of patients with dilated cardiomyopathy. ${ }^{11-13}$ The presence of infectious virus has not, however, been shown in myocardium from patients with dilated cardiomyopathy.

The other major hypothesis involves autoimmune mediated damage to myocytes. The production of autoantibodies has been described in patients with dilated cardiomyopathy, though most studies have not systematically assessed their organ specificity. ${ }^{1+15}$ Caforio et al have recently described circulating organ specific cardiac autoantibodies, by using indirect immunofluorescence and absorption studies, in a quarter of a group of patients with idiopathic dilated cardiomyopathy. ${ }^{16}$ This suggests that there may be autoimmune mechanisms operating in at least a subset of patients, but the exact relation of the antibodies to the pathogenesis and prognosis has not been defined. Further evidence for an autoimmune contribution to the pathogenesis of the disease comes from the discovery of the abnormal expression of major histocompatibility complex class II antigens on endocardium and cardiac endothelium in tissue obtained by endomyocardial biopsy and from hearts removed at transplantation. ${ }^{17}$ HLA typing of peripheral blood mononuclear cells has shown a positive association with DR4 phenotype in patients with dilated cardiomyopathy, which provides an interesting parallel with other autoimmune diseases. ${ }^{18}$ The results of a recent trial of immunosuppression in patients with dilated cardiomyopathy, in which no benefit was shown, are not surprising in view of the probable heterogeneity of both the aetiology and pathogenesis of this condition. ${ }^{19}$

The viral and the autoimmune hypotheses are not mutually exclusive. In experimental murine myocarditis infectious virus can no longer be recovered from the myocardium after two weeks, ${ }^{31320}$ although nucleic acid sequences of the viral genome are still detectable. ${ }^{1320}$ The development of chronic destruction of myocytes and myocardial fibrosis is associated with the development of circulating cardiac specific autoantibodies $^{21}$ and autoreactive lymphocytes. ${ }^{13}$ In this animal model chronic inflammation seems to be autoimmune in nature but initiated by viral infection.

Clearly we shall not be able to improve our treatment of idiopathic dilated cardiomyopathy until we understand more about the disease. Possibly, different mechanisms of disease may be operating in patients with the same clinical outcome. It is important to determine the mechanisms of pathogenesis as these may have a bearing on specific treatment, whether this is antiviral, immunosuppressive, or something else.

A L P CAFORIO Clinical Research Fellow

J T STEWART Senior Fellow

W J MCKENNA Senior Lecturer

Department of Cardiological Sciences,

St George's Hospital Medical School,

London SW 17 0RE
1 Abelmann WH, Lorell BH. The challenge of cardiomyopaths: 7 A $m$ Coll Cardiol 1989:13:1219-39. Codd MB. Sugrue DD, Gersh BJ, Melton LJ. Epidemiology of idiopathic dilated cardiomyopath and hypertrophic cardiomyopathy: a population based study in Olmstead County, MN, 1975-84. Circulation 1989:80:56+-72

3 Woodroof JF. Viral myocarditis. A review. Am f Pathol 1980;101:427-79.

4 Fuster V, Gersh BJ, Giuliani ER, Tajik AJ, Brandenburg AO, Frye RL. The natural history of idiopathic dilated cardiomyopathy. Am $\mathcal{F}$ Cardiol 1981;47:525-31.

McKenna WJ, Alfonso $\mathrm{F}$. Arrhythmias in the cardiomyopathies and mitral valve prolapse. In Zipes DP, Rowlands DJ, eds. Progress in cardiologv. Philadelphia: Lea and Febiger, 1988:59-75.

6 Heck CF, Shumway SJ, Kaye MP. The registry of the International Society for Heart Tansplantation: sixth official report - 1989. I Heart Transplant 1989;8:271-6.

Rowland E, McKenna W'J, Sugrue D, Barclay R, Foale RA, Krikler DM. Ventricular tachycardia of left bundle branch block configuration in patients with isolated right ventricular dilatation. Clinical and electrophysiological features. Br Heart 7 1984;51:15-24.

8 CONSENSUS Trial Study Group. Effects of enalapril on mortality in severe congestive heart failure: results of the cooperative north Scandinavian enalapril survival study (CONSENSUS). $N$ Engl Y Med 1987;316:1+29-35.

9 Figulla HR, Rahlf G, Nieger M, Luig H, Kreuzer H. Spontaneous hemodynamic improvement or stabilisation and associated biopsy findings in patients with congestive cardiomyopathy Circulation 1985:71:1095-104.

10 Tanganelli P, DiL.enarda A, Bianciardi G, et al. Correlation between histomorphometric findings on endomyocardial biopsy and clinical findings in idiopathic dilated cardiomyopathy. $\mathrm{Am} \mathcal{F}$ Curdiol 1989:64:504-6.

11 Bowles NE, Richardson PJ, Olsen GJ, Archard LC. Detection of Coxsackie B virus-specific RNA sequences in myocardial biopsy samples from patients with myocarditis and dilated cardiomyopathy. Lancet 1986;: 1120-3.
12 Bowles NE, Rose ML, Taylor P, et al. End-stage dilated cardiomyopathy. Persistence of enterovirus RNA in myocardium at cardiac transplantation and lack of immune response. Circulation 1989;80:1128-36.

13 Kandolf R. The impact of recombinant DNA technology on the study of enterovirus heart disease. In: Bendinelli M, Friedman H, eds. Coxsackieviruses - a general update. New York: Plenum, 1988:293-318

14 Schulteiss HP, Bolte HD. Immunological analysis of auto-antibodies against the adenine nucleotide translocator in dilated cardiomyopathy. F Mol Cell Cardiol 1985;17:603-17.

15 Maisch B, Deeg P, Liebau G, Kochsiek K. Diagnostic relevance of humoral and cytotoxic immun reactions in primary and secondary dilated cardiomyopathy. $\mathrm{Am} f$ Cardiol 1983;52:1072-8.

16 Caforio ALP, Bonifacio E, Stewart JT, et al. Novel organ-specific circulating cardiac autoantibodies in dilated cardiomyopathy. $7 \mathrm{~A} m$ Coll Cardiol (in press).

17 Caforio ALP, Stewart JT, Bonifacio E, Davies MJ, McKenna WJ, Bottazzo GF. Inappropriate major histocompatibility complex expression on cardiac tissue in dilated cardiomyopathy. Relevance for autoimmunity? fournal of Autoimmunity (in press).

18 Anderson JL, Carlquist JF, Lutz JR, DeWitt CW, Hammond EH. HLA A, B, C, and DR typing in idiopathic dilated cardiomyopathy; a search for immune response factors. Am 7 Cardiol 1984:53:1326-30.

19 Parrillo JE, Cunnion RE, Epstein SE, et al. A prospective, randomized, controlled trial of prednisolone for dilated cardiomyopathy. N Engl f Med 1989;321:1061-8.

20 Cronin ME, Love LA, Miller FW, McClintock PR, Plotz PH. The natural history of encephalomyocarditis virus-induced myositis and myocarditis in mice. Viral persistence demonstrated by in situ hybridization. $\mathcal{F} \operatorname{Exp}$ Med 1988;168:1639-48.

21 Alvarez F, Neu N, Rose NR, Craig SW, Beisel KW. Heart-specific autoantibodies induced by coxsackievirus B3: identification of heart autoantigens. Clin Immunol Immunopathol 1987;43:129-39. 